\title{
What Is the Impact of Decentralized Financial System (DFS) on Agricultural Growth in Senegal?
}

\author{
Serigne Ibrahima Diop1, François Joseph Cabral1,2 \\ ${ }^{1}$ Doctoral School Sustainable Development and Society (DSSDS), University of Thiès, Thies, Senegal \\ ${ }^{2}$ Cheikh Anta Diop University, Dakar, Senegal \\ Email: serigneibrahima.diop@univ-thies.sn, joecabral7@gmail.com
}

Received 3 August 2015; accepted 27 January 2016; published 30 January 2016

Copyright $(02016$ by authors and Scientific Research Publishing Inc.

This work is licensed under the Creative Commons Attribution International License (CC BY). http://creativecommons.org/licenses/by/4.0/

(c) (i) Open Access

\begin{abstract}
The objective of this article is to analyze the tie between the financings of the Decentralized Financial System (DFS) and the agricultural growth in Senegal. We use a linear equation model. The survey covers the active period of 1999 to 2013. Results show that the Decentralized Financial System has a positive and significant impact on the agricultural GDP in Senegal.
\end{abstract}

\section{Keywords}

Impact, Decentralized Financial System, Agricultural Growth

\section{Introduction}

Agriculture is becoming a strategic sector because of food insecurity. Hence, Government of Senegal has identified it as a priority sector in Senegal Emerging Plan (SEP). However it faces many issues among other related to the production, marketing and financing. According to Van de Walle (1990), access to funding and opportunities for productive investment is required for the participation of the poor stratums to the growth. When poor farmers have land, necessary inputs such as seeds, fertilizers and pesticides, and access to water for irrigation, they can improve the productivity of their culture. This idea is confirmed by the document of the SEP, which says that prerequisites are necessary to contribute to economic growth, among which include 1) water control, reinforcing the quality of soils; 2) the modernization of equipment; 3) improving access to quality inputs (certified seeds), to land, to markets, to adapted funding; 4) the development of chains of values; 5) technical support and agricultural advice and; 6) sector structuring and strengthening of inter profession (SEP, p. 55). Marketing is a key element for the development of the agricultural sector. Since, for a particular product, distribution channels re- 
flect to some extent the structure of the power of negotiation of suppliers and customers (LPD die Peanut, April 2003, p. 5). To protect their farmers and their agricultural economies, African countries have a tendency to protect their products or to apply preferential rate.

But this strategy was becoming less and less possible since the Treaty of the West Africa Economic and Monetary Union (WAEMU), in particular including the agreement on common external tariffs that took effect in 2000, had effect of greatly reducing tariff protections for which our agriculture took benefit. Therefore, Senegalese agriculture has to face increased competition in its home market and in the markets of the countries members of the West Africa Economic and Monetary Union (WAEMU. According to the World Bank (World Bank, 1998), in Saharan Africa, agricultural areas shelter three quarters of the population, generate 70 to 80 percent of employment, 40 to 60 percent of National Gross Income, 80 to 90 percent of export earnings and 80 to 90 percent of the food supply. This does not allow the agricultural sector to benefit fully from funding financial system.

The relationship between agriculture and financial system is often marked by many bottlenecks. The study of the relation between financial development and economic growth shows that there can be mutual interaction between the two phenomenons. An efficient financial system can contribute to economic growth, which even influences the type of the financial system as the economy can bear. Thus, the interaction and efficiency become intimately linked (Ayoub, 2003: p. 31). But Jude C. Eggoh and Patrick Villieu (2011) think the interaction between the real sectors and the financial shows multiple balances, which can produce an nonlinearity of the relationship between growth and financial. In particular, two balances may coexist: a first equilibrium where financial development and economic growth are weak, and a second equilibrium where financial system is developed and economic growth is strong. In addition, there is an indeterminacy of the relationship between financial development and growth beyond a given threshold (Jude C. Eggoh, Patrick Villieu, 2011: p. 21-22). That is why Ang (2008) thinksan efficient financial system contributes positively to economic growth (J. B, 2008: p. 38) for Ould Sidi (2008), the main contribution of financial sector to the economic growth comes from its ability to generate cash and restored an effective payment system, reliable and progressive. The development of financial system must be assessed in a positive way, since it improves the efficiency of the financial system and expands the range of financing and investment. An efficient and developed financial system is now essential to a long-term economic growth Ould Sidi, 2008: p. 1). These different analyzes show the importance that our policy makers must attach to the access to financing because of the issues of economic growth, development, poverty, job creation, that represent challenges for developing economies.

In this specific context, access to financial services, including credit should be considered as a significant need to satisfy (Meliani \& Aghrout, 2009: p. 9). The participation of agriculture to economic growth is much more felt in sub-Saharan countries. According to Niyongabo (2008), in sub-Saharan Africa, agriculture and rural areas shelter more than three quarters of the population and contribute for the largest share to employment, GDP, export earnings and food supplies. Therefore, funding for activities that develop in these areas is a key factor for growth and poverty reduction. The prediction in terms of economic growth in Senegal show that" the contribution of agriculture to growth and poverty reduction will be significant, both at national and rural levels for the next 10 to 15 years. A contribution of recent trends in agricultural sector growth would reduce the national poverty rate of 28.6 percentage points in 2015 compared to its estimated level in 2005 for the country (50.7 percent) (Cabral, 2010). To support the development of the agricultural sector and thus encourage its impact on growth, it is important to foster the institutional framework since the potential contribution of financial development to economic growth is considerable but it depends on the development of appropriate institutional structures. The liberalization of the financial system could increase the efficiency of the economy by enabling better resource allocation (Deisting, Makhlouf, \& Naaman, 2012: p. 19).

This leads us to ask questions about the effectiveness of a financial system. An efficient financial system is undoubtedly an engine for economic growth. However, its efficiency is subject to an unresolved academic debate (Ayoub, 2003: p. 31). Therefore, the question is raised to know what is the impact of the funding of Decentralized Financial System on agricultural growth in Senegal.

The essential question that the GDP asks is that the improvement of the conditions of life of an individual cannot be feared that through the increase of his/her/its personal incomes of one period T1 in relation to his/her/its incomes in T0. However the microfinance reverses this reasoning while widening the horizon of the individual’s gains (Kamalan, 2006: p. 8). Today, it is admitted generally For Meliani Hakimsétif Ahmed Ag- 
hrout' that if the micro finances arrives to reconcile the social and economic objectives, and to benefit from a suitable legislative setting, it can constitute a means efficient of poverty reduction, his/her/its fundamental principles being based on the confidence, solidarity and the mutual help” (Meliani \& Aghrout, 2009: p. 9). The financial system grants little importance to the agricultural financing although agriculture greatly contributes to the development of the country. This problem seems to be world, because in Latin America it leaves from the agricultural credit wallet is negligible. On the 108 institutions of financial of development, only 32 intervenes in the sector of the farming financing and or agricultural (Travellli, 2007). In Mali the quasi-totality of the producers has of exploited them Domestic Agricultural, very often of small and middle sizes, under equipped and without access to no system of financing outside of the zones of cultures to big potential (rice, cotton) (Coulibaly, 2008).

According to Doligez (2002), the institutions of micro finance have the capacity to widen the markets of credit at a time in terms geographical (cover territorial) and social. For Guiheneuf (2000), the credit plays a big role in the development of the agricultural activities in the world, but these are varied very and the systems of credit greatly bound to history, to the importance of the state and the collective organizations. For Guérin on the social plan the micro finances contributed to emancipation and the woman's promotion, she/it is susceptible to encourage the autonomy of the women, even poorest while helping them to start or to consolidate an activity and to avoid some dependences (Guerin, 2010). But Labiate thinks that the micro finances arrived with microcrédits to finance funds of rolling of short term and small credits of investments. For Henintsoa (2008), the promotion of the microfinance presents itself like a previous condition to the farming growth through the access to financings. Indeed, the financial liberalization encourages the increase of the credit offer and consequently, the decrease of the costs of access to this financing notably for the poor peasants.

The objective of this article is to analyze the link between Decentralized Financial Systems (DFS) and the agricultural growth in Senegal.

In the developments that follow, facts stylized on the financing of agriculture will first be put in inscription (part 1). The methodology is exposed then (part 2). The results and findings of economic policies will finally be pulled (part 3).

\section{Agricultural Sector Financing}

The financing of agriculture reveals increasingly the financial sector despite high risks. The tables below and the graph give us the distribution of funding by the financial sector.

The analysis of Table 1 shows that the decentralized financial system grants meadows $7.36 \%$ of its financing to the agricultural sector. This rate improved during the last two years. It is respectively of $11.59 \%$ and $11.01 \%$ in 2012 and 2013. The share of funding allocated to the agricultural sector is very low. This situation is explained by the higher level of risk in agriculture.

The analysis of Figure 1 shows that the DSF have parts of outstanding credits that are very weak. This part had increased between 2006 and 2008. This period coincided with the setting in work and the adoption of the new regulation of the sector of the micro finances that had as between objective to purify the sector. From 2009 year of application of the law, the rate of unpaid lowered strongly, what improved the wallet of the DFS.

\section{Methodology}

\subsection{Analysis Period}

The study was conducted over a period of fifteen (15) years (1999-2013) and from data consolidated agricultural portfolios of the three largest networks of Senegal that are the Federation of Mutual Credit Offices of Senegal (FMCS), the Union of the Mutual Credit and Savings Alliance for Production (UM-CSAP) and the Union of Mutual Partnership for Mobilizing Savings and Credit in Senegal (UM-PMSCS) These three networks represent $79 \%$ of savings deposits and $76 \%$ of the total outstanding sector credit DRS-DFS Report, 2008).

\subsection{Model Specification}

There are two types of variables in the economic model: exogenous variable or explanatory variables and endogenous variables, or variables to explain. The exogenous variables are the explanatory variables of the studied 
Table 1. Part of agriculture in the financing of the DFS in 1999-2013.

\begin{tabular}{cccc}
\hline Anneees & $\begin{array}{c}\text { DFS credits to the agricultural } \\
\text { sector (in thousands) }\end{array}$ & $\begin{array}{c}\text { DFS total credits } \\
\text { (in thousands) }\end{array}$ & $\begin{array}{c}\text { DFS agricultural } \\
\text { credits/total DFS credit (\%) }\end{array}$ \\
\hline 1999 & $1,485,586$ & $12,193,932$ & 12.18 \\
2000 & $2,025,323$ & $16,651,724$ & 12.16 \\
2001 & $1,413,576$ & $18,413,970$ & 7.68 \\
2002 & $1,115,317$ & $22,930,098$ & 4.86 \\
2003 & $2,231,925$ & $31,376,966$ & 7.11 \\
2004 & $2,705,148$ & $45,682,468$ & 5.92 \\
2005 & $2,909,894$ & $66,630,160$ & 3.37 \\
2006 & $2,409,963$ & $73,585,832$ & 3.28 \\
2007 & $3,158,481$ & $92,122,131$ & 3.43 \\
2008 & $3,702,016$ & $111,479,912$ & 3.32 \\
2009 & $7,647,740$ & $119,894,014$ & 6.38 \\
2010 & $9,956,902$ & $137,240,009$ & 7.26 \\
2011 & $12,984,360$ & $155,132,741$ & 8.37 \\
2012 & $18,332,865$ & $158,208,571$ & 11.59 \\
2013 & $18,274,606$ & $165,916,801$ & 11.01 \\
\hline
\end{tabular}

Sources: Calculations from data FMCS, UM-CSAP and UM-PMSCS.

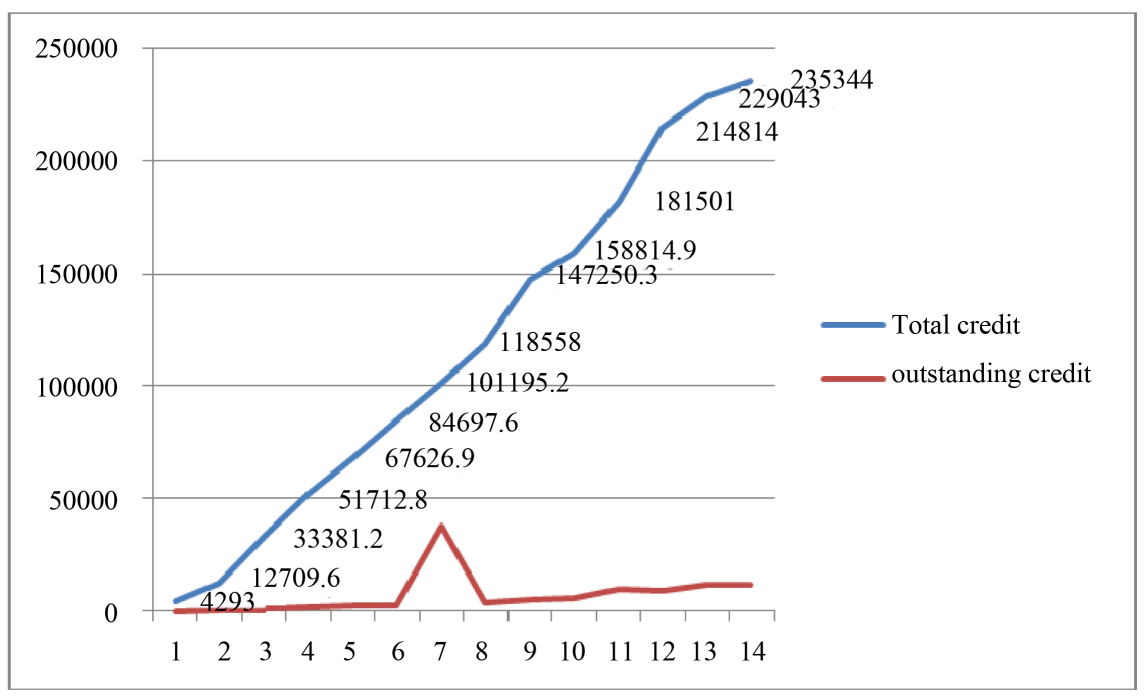

Figure 1. Part credit outstanding DFS of 2000 to 2013 in thousands. Sources: calculations from BCEAO data FMCS, UM-CSAP and UM-PMSCS.

variable.

1) Endogenous variable

o Agricultural GDP (AGDP)

Agricultural GDP represents the share of agriculture in the Gross Domestic Product (GDP) during one year.

2) Exogenous variables

The variables are:

o Agricultural Credit sector DFS (ACDFS)

There are short credits, medium and long terms granted by the three networks that are FMCS, the UM-CSAP 
and UM-PMSCS to the agricultural sector.

o Agricultural GDP per farmer (AGDP/F)

Agricultural GDP per rural living

o Rainfall (PLUV)

Average precipitation level

o Gross Capital Formation in the agricultural sector (GCFA)

Gross Capital Formation in the agricultural sector includes the assets used in the production process, namely the developed land, irrigation works, structures, machinery and tools.

o Degree of educational development (DED)

Gross primary enrollment

o Percentage change in the consumer price index (PCCPI)

o Subsidy granted to the agricultural sector (SUBA)

This is the annual subsidies for seeds, fertilizers, pesticides, agricultural equipment and the price to the producer.

\subsection{Econometric Estimation of the Model}

Several models have been developed to study the relationship between financial development and growth. But as part of our study, we draw the linear equation model developed by Levine (2005). The relationship between the variables of financial development and economic growth will be studied using a linear equation model.

To study the relationship between financial development and agricultural growth in the long term, we estimate the model specified in the following equation:

$$
\begin{aligned}
(\text { AGDP })_{\mathrm{t}}-(\text { AGDP })_{\mathrm{t}-1}= & \mathrm{C}+\mathrm{a}_{1}(\text { DF })+\mathrm{a}_{2}(\text { AGDP } / \mathrm{F})+\mathrm{a}_{3}(\text { PLUV }) \\
& +\mathrm{a}_{4}(\text { GCFA })+\mathrm{a}_{5}(\text { DED })+\mathrm{a}_{6}(\text { PCCPI })+\varepsilon
\end{aligned}
$$

where $\mathrm{C}$ is the constant, the coefficients are the parameters of the different variables to estimate, DF degree of financial development or credit DFS to the agricultural sector (ACDFS), "AGDP/F" Agricultural GDP per rural living, "PLUV" average precipitation, GCFA Gross Capital Formation in agriculture, "DED" Degree of educational development, "PCCPI" Percentage change in the consumer price index and $\varepsilon$ a random variable that measures the error term.

The estimation will be made by the ordinary least squares method.

The original model will be transformed into model for estimating Log in Eviews 4

\subsection{Estimation Including Variable "Subsidies"}

A second test will be performed with the same model that will integrate the variable subsidy. Indeed, the subsidy s started from the year 2000, to see its impact on the quality of results, it is considered necessary to repeat the tests with the same model that in addition to the above variables are used incorporates variable grant. The specified model is the following:

$$
\begin{aligned}
(\text { AGDP })_{\mathrm{t}}-(\text { AGDP })_{\mathrm{t}-1}= & \mathrm{C}+\mathrm{a}_{1}(\text { DF })+\mathrm{a}_{2}(\text { AGDP } / \mathrm{F})+\mathrm{a}_{3}(\text { PLUV })+\mathrm{a}_{4}(\text { GCFA }) \\
& +\mathrm{a}_{5}(\text { DED })+\mathrm{a}_{6}(\text { PCCPI })+\mathrm{a}_{7}(\text { SUBA })+\varepsilon
\end{aligned}
$$

\section{Results}

The results of the estimation show that credits allocated by the Decentralized Financial System (DFS) have a significant impact on the agricultural growth. A 10\% increase in credit granted by DFS to the agricultural sector (ACDFS) leads to a growth of $0.72 \%$ of the Agricultural GDP. The microfinance sector is characterized by micro credit dedicated to agricultural producers. These financings are mostly cash loans. These credits in addition to promote the purchase of inputs, allow producers to buy welding supplies. Producers and traders in harvest period are financed. So they can buy the production. The Decentralized Financial System (DFS) mostly finance pluvial crops and farms for seasonal loans. Financing is more efficient in the absence of subsidy.

Grants allow producers to acquire equipments. The savings are achieved in the acquisition of subsidized inputs and can be reinvested in the production equipment, which positively affects growth. On the other side, the 
equipment grant facilitates the renewal of obsolete farm equipment.

An increase of $10 \%$ of the Gross Capital Formation in the agricultural sector (GCFA) causes a increase by $13.15 \%$ of Agricultural GDP. This shows that funding can have important effects on accumulation and hence agricultural growth.

\section{Conclusion and Policy Lessons}

DFS finance small producers by ensuring the production of grain and other commodities are derived from pluvial in view of food security. The improvement of the financial mechanism, through the establishment of guarantee funds, would be necessary to increase the volume funding for the agricultural sector. These small grants do not allow huge investment in agriculture, but they incite to emergence of small and medium enterprises and hence to contribute on agricultural growth.

\section{References}

Aghrout, S. A., \& Meliani, H. (2009). Research Fellow (pp. 1-16). Salford: Development of Islamic Microfinance, Challenges and Prospects, Salford University.

Ang, J. B. (2008). What Are the Mechanisms Linking Financial Development and Economic Growth in Malaysia? Economic Modeling, 25, 38-53. http://dx.doi.org/10.1016/j.econmod.2007.04.006

Ayoub, H. (2003). The Reforms of the Lebanese Financial System, They Contribute to Improve Efficiency. Centre for Studies in International Macroeconomics and Finance Research Work No, University of Nice-Sophia Antipolis, 1-41

Cabral, F. J. (2010). Is Senegalese Growth Strategy Pro-Poor? Journal of Economics and International Finance, 2, $144-155$.

Coulibaly, I. (2008). The Pro-Poor Growth and the Role of Agriculture in Mali, Communication on: To Get Lasting Financings for Agriculture. CNOP/Mali.

Deisting, F., Makhlouf, F., \& Naaman, A. (2012). Financial Development, Financial Flows and Economic Growth. CATT WP No. 10 June 2012, 1-29.

Doligez, F. (2002). Ten Years of Survey of the Impact of the Microfinance: Synthesis of Some Observations of Land. 88112.

Eggoh, J. C., \& Villieu, P. (2011). A Review of the Unlinearity between Financial Development and Economic Growth. A Ngevien Research Group in Economics and Management (GRANEM), Angers: University of Angers, 1-28.

Guiheneuf, P. Y. (2000) Dans sa revue “Financer l'agriculture”.

Guérin, S. K., \& Agier, I. (2010). Microfinance and Women's Empowerment: Do Relationships between Women Matter? Lessons from Rural Southern Indiana, November 1-19.

Henintsoa, C. M. (2008). Role of the Microfinance in the Farming Development, Memory for the Obtaining of the Mastery Diploma Is Economics. Universty d'Antananarivo Law School, of Economy, Management and Sociology Department Economy Option: Macroeconomics and Modelling, 1-76.

Kamalan, E. A. (2006). Under What Conditions Microfinance Will Help Institutions from Southern Countries to Economic Development? Proceedings of the Science Meeting of the Network "Economic Analysis and Development", Paris, 7-8 September 2006, 1-12.

Niyongabo, E. (2008). Challenges of Agricultural and Rural Finance, Microfinance Role and Implications for Public Policy in SSA. Research Paths Based on the Case of Burundi, Working Paper: 2008/6 Research Centre Warocque, 1-31.

Ould Sidi, M. E. M. (2008). Bergamo Development Financial and Economic Growth in Mauritania: Opportunities and Conditions. African Review of Money Finance and Banking, 23-44.

Travellli, C. H. V. (2007). Agricultural Development Banks: Latin American Experiences. Carolina Trivelli Hildegardi Venero December 2007.

Van de Walle, D. (1990). Policies for Reducing Poverty. Development and Finance, 27, 6-8.

World Bank (1998). World Bank's Strategy for the Development of Microfinance and Financial Services to SMEs and Rural Sub-Saharan Africa. Washington DC: Private Sector and Finance Group, Africa Region, World Bank. 